OPEN ACCESS

Approved by:

Frontiers Editorial Office

Frontiers Media SA, Switzerland

*Correspondence:

Alice Geminiani

alice.geminiani@polimi.it

Received: 20 June 2019 Accepted: 26 June 2019

Published: 19 July 2019

Citation: Geminiani A, Casellato C, D'Angelo E and Pedrocchi A (2019) Corrigendum:

Complex Electroresponsive Dynamics in Olivocerebellar Neurons Represented With

Extended-Generalized Leaky Integrate and Fire Models.

Front. Comput. Neurosci. 13:48. doi: 10.3389/fncom.2019.00048

\section{Corrigendum: Complex} Electroresponsive Dynamics in Olivocerebellar Neurons Represented With Extended-Generalized Leaky Integrate and Fire Models

\author{
Alice Geminiani ${ }^{1 *}$, Claudia Casellato ${ }^{2}$, Egidio D'Angelo ${ }^{2,3}$ and Alessandra Pedrocchi ${ }^{1}$ \\ ${ }^{1}$ NEARLab, Department of Electronics, Information and Bioengineering, Politecnico di Milano, Milan, Italy, ${ }^{2}$ Department of \\ Brain and Behavioral Sciences, University of Pavia, Pavia, Italy, ${ }^{3}$ IRCCS Mondino Foundation, Pavia, Italy
}

Keywords: neuronal modeling, point neuron, neuron model simplification, neuronal electroresponsiveness, olivocerebellar neurons

\section{A Corrigendum on}

Complex Electroresponsive Dynamics in Olivocerebellar Neurons Represented With Extended-Generalized Leaky Integrate and Fire Models

by Geminiani, A., Casellato, C., D'Angelo, E., and Pedrocchi, A. (2019). Front. Comput. Neurosci. 13:35. doi: 10.3389/fncom.2019.00035

In the published article, there was an error regarding the affiliations for "Egidio D'Angelo." As well as having affiliation 2, he should also have IRCCS Mondino Foundation, Pavia Italy. The authors apologize for this error and state that this does not change the scientific conclusions of the article in any way. The original article has been updated.

Copyright $\odot 2019$ Geminiani, Casellato, D'Angelo and Pedrocchi. This is an open-access article distributed under the terms of the Creative Commons Attribution License (CC BY). The use, distribution or reproduction in other forums is permitted, provided the original author(s) and the copyright owner(s) are credited and that the original publication in this journal is cited, in accordance with accepted academic practice. No use, distribution or reproduction is permitted which does not comply with these terms. 